says Sander. One of the problems with checking the data is that the absorption spectra of chloride compounds are technically challenging to determine. Sander's group used a new technique to synthesize and purify $\mathrm{Cl}_{2} \mathrm{O}_{2}$. To avoid impurities and exclude secondary reactions, the team trapped the molecule at low temperatures, then slowly warmed it up.

"Reactions in experimental chambers are one thing - the free atmosphere is something else," says Joe Farman, one of the scientists who first quantified the ozone hole over Antarctica ${ }^{3}$. "There's no doubt that ozone disappears at up to $3 \%$ a day - whether or not we completely understand the chemistry." But he adds that insufficient control of substances such as halon 1301, used as a flame suppressor, and HCFC22, a refrigerant, is a bigger threat to the success of the Montreal Protocol than are models that don't match the observed losses.

\section{Hot topic}

Meanwhile, atmosphere researchers have started to think about how to reconcile observations of ozone depletion with the new chemical models. Several thermal reactions, or combinations of reactions, could fill the gap. Sander's group has started to study possible candidates one by one - but so far without success.

Rex thinks that a chemical pathway involving a $\mathrm{Cl}_{2} \mathrm{O}_{2}$ isomer - a molecule with the same atoms but a different structure - might be at play. But even if the basic chemical model of ozone destruction is upheld, the temperature dependency of key reactions in the process could be very different - or even opposite from thought. This could have dramatic consequences for the understanding of links between climate change and ozone loss, Rex says.

The new measurements raise "intriguing questions", but don't compromise the Montreal Protocol as such, says John Pyle, an atmosphere researcher at the University of Cambridge. "We're starting to see the benefits of the protocol, but we need to keep the pressure on." He says that he finds it "extremely hard to believe" that an unknown mechanism accounts for the bulk of observed ozone losses.

Nothing currently suggests that the role of CFCs must be called into question, Rex stresses. "Overwhelming evidence still suggests that anthropogenic emissions of CFCs and halons are the reason for the ozone loss. But we would be on much firmer ground if we could write down the correct chemical reactions." Quirin Schiermeier

1. Pope, F. D., Hansen, J. C., Bayes, K. D., Friedl, R. R. \& Sander, S. P. J. Phys. Chem. A 111, 4322-4332 (2007)

2. Molina, L. T. \& Molina, M. J. J. Phys. Chem. 91, 433-436 (1987).

3. Farman, J. C., Gardiner, B. G. \& Shanklin, J. D. Nature 315 207-210 (1985).

\title{
Pressure for environmental disclosure increases
}

\begin{abstract}
Companies are increasingly acknowledging the risks posed by global warming, suggest surveys released on 24 September. The latest Global Corporate Climate Change Report, released by the advocacy group Carbon Disclosure Project (CDP) at an event in New York headlined by former US President Bill Clinton, details disclosures of energy costs from more than 1,300 companies around the world (see graphic).

The London-based group of institutional investors is campaigning for the right of shareholders to probe the environmental policies of firms in which they invest. It argues that the possibility of real damages from global warming and the almost certain introduction of regulations penalizing emissions of carbon dioxide and other greenhouse gases mean that climate now poses a material liability to many companies that should
\end{abstract}

be publicly disclosed. $\mathrm{CDP}$ is leveraging investor pressure to push for voluntary disclosure, but others have opted for brute force. New York Attorney General Andrew Cuomo issued subpoenas on 14 September for internal documents from five companies planning to build new coal-fired power plants, questioning whether they have fully disclosed the financial risks of increasing their greenhouse-gas emissions. Ceres, a coalition of environmentalists and investors, and Environmental Defense, a non-profit organization based in $\mathrm{New}$ York, followed up days later with a petition to the US Securities and Exchange Commission seeking to increase financial disclosure requirements on corporate exposure to 'climate risk'.

On Monday, Wal-Mart announced that it intends to ask its suppliers for the

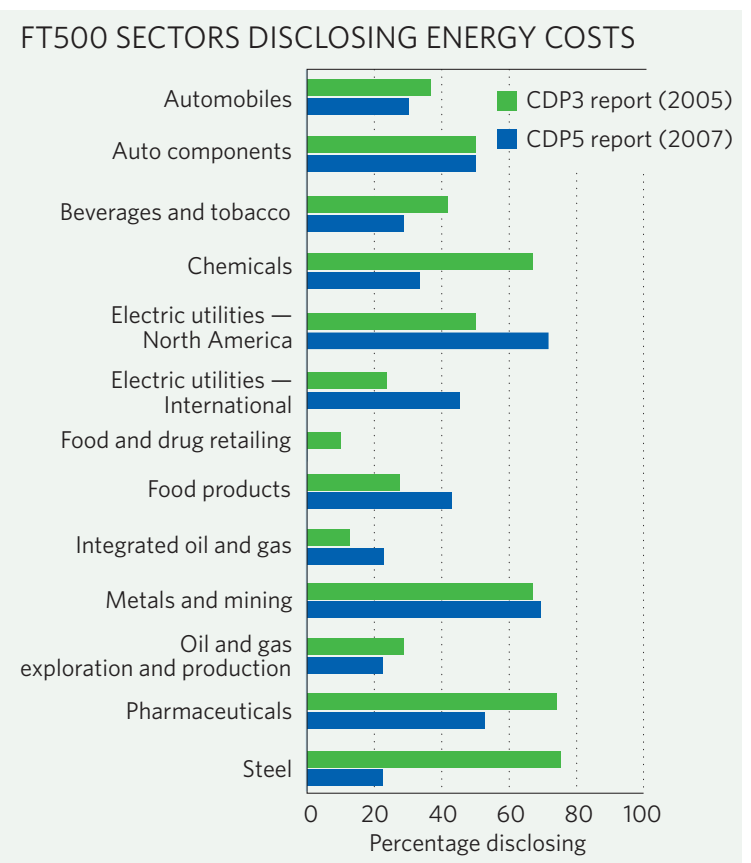

energy costs involved in manufacturing seven of its product lines. The retail chain will then work with CDP to translate this information into greenhouse-gas emission figures.

"It will be money coordinated through Wall Street that builds the energyefficient economy of the twenty-first century," says CDP head Paul Dickinson. "There are risks, but there are also big opportunities."

CDP asked firms to assess the risks - and opportunities - presented by global warming, and to describe any strategies being used to reduce greenhouse-gas emissions. The survey, signed by more than 300 institutional investors managing some US\$41 trillion in assets, found that $76 \%$ of respondents reported implementation of a programme to reduce greenhouse-gas emissions, compared with $48 \%$ a year ago. The percentages of respondents who thought global warming posed an economic threat and of those who believed it offered opportunities were roughly equal, at $79 \%$ and $82 \%$, respectively.

This is the fifth annual report by CDP, and the statistics indicate some success: $77 \%$ of the world's 500 largest companies responded, compared with $47 \%$ in 2002. European firms led the way with $83 \%$ participating. North American firms gained some ground with a $74 \%$ response rate, compared with $66 \%$ last year. Among the large firms that did not respond were Apple Computer, Philips Electronics and Gazprom. Jeff Tollefson 